\title{
Propensity Score-Matched Analysis of Open Surgical and Endovascular Repair for Type B Aortic Dissection
}

\author{
Michael E. Brunt, Natalia N. Egorova, and Alan J. Moskowitz \\ Department of Health Evidence and Policy, Mount Sinai School of Medicine, One Gustave L. Levy Place, P.O. Box 1077, New York, \\ NY 10029, USA \\ Correspondence should be addressed to Natalia N. Egorova, natalia.egorova@mountsinai.org
}

Received 31 December 2010; Accepted 10 July 2011

Academic Editor: John A. Kern

Copyright (๑) 2011 Michael E. Brunt et al. This is an open access article distributed under the Creative Commons Attribution License, which permits unrestricted use, distribution, and reproduction in any medium, provided the original work is properly cited.

Objective. To identify national outcomes of thoracic endovascular aortic repair (TEVAR) for type B aortic dissections (TBADs). Methods. The Nationwide Inpatient Sample database was examined from 2005 to 2008 using ICD-9 codes to identify patients with TBAD who underwent TEVAR or open surgical repair. We constructed separate propensity models for emergently and electively admitted patients and calculated mortality and complication rates for propensity score-matched cohorts of TEVAR and open repair patients. Results. In-hospital mortality was significantly higher following open repair than TEVAR (17.5\% versus $10.8 \%, P=.045)$ in emergently admitted TBAD. There was no in-hospital mortality difference between open repair and TEVAR $(5.6 \%$ versus $3.3 \%$, $P=.464)$ for elective admissions. Hospitals performing thirty or more TEVAR procedures annually had lower mortality for emergent TBAD than hospitals with fewer than thirty procedures. Conclusions. TEVAR produces better in-hospital outcomes in emergent TBAD than open repair, but further longitudinal analysis is required.

\section{Background}

Aortic dissection is a rare condition, with annual incidence of three to eight cases/100,000 people [1-3], which is associated with high morbidity and mortality. Type A aortic dissections are viewed as surgical emergencies, but the treatment of type $\mathrm{B}$ aortic dissections (TBADs), which account for about onethird of total aortic dissections [4], is more variable. Acute type $\mathrm{B}$ dissections that are complicated by visceral or limb ischemia, aortic rupture, refractory pain, or rapidly expanding dissection also require surgical intervention [5]. In the absence of such complications, which is the case for seventy percent of patients with acute type B dissection [6], medical therapy with antihypertensives has been the standard of care.

In 2005, the US Food and Drug Administration approved thoracic endovascular aortic repair (TEVAR) for the repair of thoracic aortic aneurysms [7], and surgeons have increasingly been using TEVAR off-label to treat TBAD. The high mortality rates associated with traditional open thoracotomy surgical repair of complicated TBAD have driven the increased adoption of the less invasive TEVAR in complicated TBAD. The possibility that TEVAR can facilitate better remodeling of the aorta than medical therapy and avert late aortic rupture has stimulated its use in treating uncomplicated TBAD patients, who traditionally would have received medical therapy alone $[8,9]$.

Most studies on the outcomes of TEVAR have been small, single center studies $[10,11]$, or meta-analyses with potential selection biases $[5,12]$, but Sachs et al. [13] were the first to conduct a large population study utilizing the Nationwide Inpatient Sample which compared the outcomes of treatment with TEVAR versus open surgery in TBAD patients. Our study expands on the work done by Sachs et al. [13], as we include an additional year of data (2008) and utilize a propensity score matching approach that more effectively controls for differences between treatment groups than standard multivariate analysis. Moreover, we examine the relationship between volume and outcome of TEVAR procedures. 


\section{Materials and Methods}

2.1. Data Sources and Study Population. We used the Nationwide Inpatient Sample (NIS) database to identify patients with type B thoracic aortic dissections who underwent surgical repair between 2005 and 2008. The NIS is the largest all-payer inpatient care database and contains discharge data from over eight million hospitalizations per year, which is approximately twenty percent of all hospitalizations in the United States.

International Classification of Diseases, the 9th edition (ICD-9) diagnosis codes were used to identify all patients in the NIS with thoracic aortic dissections (441.01). Patients with thoracic dissections treated surgically were separated from those receiving medical therapy alone by using procedure codes for endovascular stent graft repair (39.73) or open repair $(38.34,38.45)$. The ICD-9 procedure code for TEVAR was introduced in September 2005, which limited our study to the period from 2005 to 2008. Additionally, we excluded all patients with diagnosis codes for aortic aneurysms (441.1 to 441.9), to better restrict the analysis to patients with acute dissection. We isolated type B aortic dissections from type A aortic dissections using criteria developed by Sachs et al. [13], in which patients with procedure codes for cardioplegia (39.63), valve repair (35.00-35.99), or operations on vessels of the heart $(36.00-36.99,37.0,37.2,37.31-37.90,37.93-$ 37.99), who were more likely to have type A dissections, were excluded. We further stratified the patients with type B dissections based on whether they were admitted emergently or electively to the hospital.

The following patient demographics and hospital characteristics were identified: age, gender, hospital bed size, hospital teaching status, and annual volume of TEVAR performed per hospital. The following comorbidities were assessed: cardiac arrhythmias, chronic congestive heart failure $(\mathrm{CHF})$, coronary artery disease, valvular heart disease, chronic pulmonary disease, chronic renal failure, coagulopathy, deficiency anemias, diabetes, hypertension, obesity, neurological disorders, paralysis, and peripheral vascular disease (Table 1).

2.2. Statistical Analysis. In order to control for imbalances of patient characteristics and institutional characteristics among the treatment groups that might influence treatment outcome, we used a propensity scoring method to establish matched cohorts. Separate models were created for emergent and elective admissions. A propensity score, which was assigned to each hospitalization, was based on a multivariate logistic regression model that examined the impact of thirty variables (patient demographics, comorbidities, and hospital characteristics) on the likelihood of treatment assignment. Patients with similar propensity scores in the two treatment groups were matched using a 1-to-1 scheme without replacement, using 8-to-1 digit match.

Outcomes were compared between propensity scorematched cohorts of patients undergoing TEVAR and open surgery. The primary outcomes measured were in-hospital mortality, in-hospital complications, and length of stay (LOS). Complications included acute renal failure, cardiac complications, neurological complications, paraplegia, posthemorrhagic anemia, postoperative hemorrhage, pulmonary complications, stroke, and thrombectomy/embolectomy. The ICD-9 diagnosis codes used to code for comorbidities and complications are provided in Table 1. Paired $t$-test was used for comparisons of continuous variables and the McNemar test for categorical variables in matched cohorts. All statistical analyses were performed using SAS 9.2 software (SAS Institute Inc., Cary, NC).

\section{Results}

3.1. Baseline Demographics and Comorbidities. During the period 2005-2008, 4752 emergently admitted patients with TBAD were treated surgically: 3427 (72.1\%) underwent open repair, and 1325 (27.9\%) underwent TEVAR (Table 2). During this same period of time, 1247 electively admitted patients with TBAD were treated surgically: 680 (54.5\%) underwent open repair, and 567 (45.5\%) underwent TEVAR (Table 3 ). Among those admitted emergently, TEVAR recipients were significantly more likely to have coronary artery disease, chronic pulmonary disease, diabetes, peripheral vascular disease and to be treated in hospitals with higher TEVAR volume. In contrast, open repair patients had higher rates of cardiac arrhythmia, valvular disease, and coagulopathy (Table 2). Among electively admitted patients, TEVAR recipients were older, had higher rates of diabetes, hypertension, and were more likely to receive their care at higher TEVAR volume hospitals. Open repair patients had significantly higher rates of valvular disease and coagulopathy (Table 3 ).

3.2. Outcomes. Propensity score matching in the emergentlyadmitted TBAD patients produced 991 matched pairs. Demographic traits and comorbidities were balanced between these matched cohorts (Table 2). The $P$ value for the Hosmer-Lemeshow goodness-of-fit test of the propensity score model was 0.605 , and the $c$ statistic was 0.828 . Inhospital mortality among emergently admitted patients was significantly higher among open repair recipients than in TEVAR recipients $(17.5 \%$ versus $10.8 \%, P=.045)$. Open repair was associated with higher rates of acute renal failure (27.3\% versus $16.8 \%, P=.008)$, cardiac complications (16.6\% versus $8.9 \%, P=.029$ ), and posthemorrhagic anemia (22.6\% versus $12.1 \%, P=.006)$ (Table 4$)$.

Propensity score matching in electively admitted TBAD patients produced 282 matched pairs. Demographic characteristics and comorbid conditions were similar between these two matched cohorts (Table 3 ). The $P$ value for the HosmerLemeshow goodness-of-fit was 0.137 , and the $c$ statistic was 0.858 . In-hospital mortality was not significantly different among recipients of TEVAR and open surgery (5.6\% versus $3.3 \%, P=.464)$. Open repair recipients did have higher rates of in-hospital complications such as acute renal failure (13.0\% versus $1.7 \%, P=.021)$, cardiac complications $(15.8 \%$ versus $3.6 \%, P=.021)$, posthemorrhagic anemia $(17.3 \%$ versus $3.5 \%, P=.017)$, postoperative hemorrhage $(19.1 \%$ 
TABLE 1: List of ICD-9 codes for comorbidities and complications.

(a)

\begin{tabular}{|c|c|}
\hline Comorbidity & ICD-9 code \\
\hline Cardiac arrhythmia & $426.0,426.10,426.11,426.12,426.13,426.7,426.9,427.0,427.1,427.2,427.3,427.9$, V45.0, V53.3 \\
\hline Chronic CHF & $\begin{array}{l}398.91,402.01,402.11,402.91,404.01,404.03,404.11,404.91,404.13,404.93,425.4,425.5,425.7, \\
425.8,425.9,428.0,428.1,428.20,428.22,428.30,428.32,428.40,428.42,428.9\end{array}$ \\
\hline Coronary disease & $412,413,414,429.2$ \\
\hline Valvular disease & $093.2,394,395,396,397,424,746.3,746.4,746.5,746.6, \mathrm{~V} 42.2, \mathrm{~V} 43.3$ \\
\hline Cardiac comorbidities & Any of the codes for cardiac arrhythmia, chronic CHF, coronary disease, or valvular disease \\
\hline Chronic pulmonary disease & $\begin{array}{l}416,417.9,490,491,492,493,494,495.0,495.1,495.2,495.3,495.4,495.5,495.6,495.8,495.9,496 \\
500,501,502,503,504,505,506.0,506.2,506.4,506.9,508.1,508.8,508.9\end{array}$ \\
\hline Chronic renal failure & $\begin{array}{l}\text { 403.01, 403.11, 403.91, 404.02, 404.03, 404.12, 404.13,404.92, 404.93, 585, 586, V42.0, V45.1, } \\
\text { V56.0-V56.2, V56.8 }\end{array}$ \\
\hline Coagulopathy & $2860-2869,287.1,287.3-287.5,289.81-289.82$ \\
\hline Deficiency anemias & $280.1-281.9,285.21-285.29,285.9$ \\
\hline Diabetes & 250 \\
\hline Hypertension & $\begin{array}{l}\text { 401.0, 401.1, 401.9, 402.00, 402.10, 402.90, 403.00, 403.10, 403.90, 404.00, 404.10, 404.90, 405.01, } \\
405.09,405.11,405.19,405.91,405.99,462.24,642.00-642.04,642.10,642.70-642.94\end{array}$ \\
\hline Obesity & $\begin{array}{l}\text { 278.0, 278.00, 278.01, V85.30, V85.31, V85.32, V85.33, V85.34, V85.35, V85.36, V85.37, V85.38, } \\
\text { V85.39, V85.4, V85.54 }\end{array}$ \\
\hline Other neurological disorders & $\begin{array}{l}330.0-331.9,332.0,333.4,333.5,334.0-335.9,333.71,333.72,333.79,333.85,333.94,338.0,340, \\
341.1-341.9,345.00-345.11,345.2-345.3,345.40-345.91,34700,34701,34710,34711,348.1, \\
348.3-348.39,780.3,780.39,784.3\end{array}$ \\
\hline Paralysis & $342.0-342.12,342.9-344.9,438.20-438.53$ \\
\hline Peripheral vascular disease & $440.0-440.9,441.00-441.9,442.0-442.9,443.1-443.9,444.21,444.22,449,447.1,557.1,557.9, \mathrm{~V} 43.4$ \\
\hline & (b) \\
\hline Complication & ICD-9 code \\
\hline Acute renal failure & 584 \\
\hline Cardiac complications & $\begin{array}{l}410.00,410.01,410.10,410.11,410.20,410.21,410.30,410.31,410.40,410.41,410.50,410.51, \\
410.60,410.61,410.70,410.71,410.80,410.81,410.90,410.91,411.0,411.1,411.81,411.89,427.5 \text {, } \\
428.21,428.3,428.31,428.32,428.41,428.43,997.1\end{array}$ \\
\hline Neurological complications & 780.01344 .1997 .02997 .0435 436, 437.1 \\
\hline Paraplegia & 344.1 \\
\hline Posthemorrhagic anemia & 285.1 \\
\hline Postoperative hemorrhage & 998.1 \\
\hline Pulmonary complications & $\begin{array}{l}311,312.9,415.0,415.11,415.12,415.19,481,482.0,482.1,482.2,482.30,482.31,482.32,482.39, \\
482.81,482.82,482.83,482.84,482.89,482.9,485,486,518.0,518.4,518.82,518.84,528.81,997.3\end{array}$ \\
\hline Stroke & 997.02 \\
\hline Thrombectomy or embolectomy & $y \quad 38.03,38.04,38.06,38.08$ \\
\hline
\end{tabular}

versus $5.2 \%, P=.009)$, and pulmonary complications (35.0\% versus $16.2 \%, P=.034$ ) (Table 5$)$.

3.3. TEVAR Volume-Mortality Relationship. To determine whether outcomes of TEVAR treatment for TBAD are related to overall hospital experience with this procedure (i.e., for aneurysms and dissection), we grouped hospitals by overall TEVAR volume and compared in-hospital TBAD mortality rates. We limited the analysis to TBAD patients admitted emergently to help control for patient differences (Figure 1). The cut-off volumes for the six TEVAR volume groups were established so that each group would have a similar number of emergently admitted TBAD patients treated with TEVAR. The lowest volume group (1-4 TEVAR procedures/year) has the highest mortality rate (13.4\%). The highest volume group (over 55 TEVAR procedures/year) has the lowest mortality rate $(2.9 \%)$. The TBAD mortality rate, which was relatively uniform at lower volumes, declined steadily as 
TABLE 2: Baseline characteristics of emergently admitted patients undergoing open surgical repair or TEVAR for type B dissections from 2005 to 2008.

\begin{tabular}{|c|c|c|c|c|c|c|}
\hline \multirow[t]{2}{*}{ Variable } & \multicolumn{3}{|c|}{ Unmatched cohort } & \multicolumn{3}{|c|}{ Matched cohort } \\
\hline & $\begin{array}{c}\text { Open repair } \\
(n=3427)\end{array}$ & $\begin{array}{c}\text { TEVAR } \\
(n=1325)\end{array}$ & $P$ value & $\begin{array}{c}\text { Open repair } \\
(n=991)\end{array}$ & $\begin{array}{c}\text { TEVAR } \\
(n=991)\end{array}$ & $P$ value \\
\hline & \multicolumn{3}{|c|}{ Mean or $\%$ of patients } & \multicolumn{3}{|c|}{ Mean or $\%$ of patients } \\
\hline Female sex & 37.2 & 38.9 & 0.642 & 35.5 & 40.4 & 0.309 \\
\hline \multicolumn{7}{|l|}{ Age } \\
\hline Mean age (years) & 59.9 & 61.2 & 0.153 & 61.9 & 61.0 & 0.429 \\
\hline$<60 \mathrm{yr}$ & 47.3 & 39.8 & 0.027 & 37.0 & 38.1 & 0.826 \\
\hline $60-64$ yr & 10.5 & 12.9 & 0.302 & 12.2 & 12.8 & 0.868 \\
\hline $65-69$ yr & 11.5 & 10.6 & 0.701 & 14.1 & 12.2 & 0.576 \\
\hline $70-74$ yr & 9.9 & 11.9 & 0.393 & 13.0 & 13.5 & 0.890 \\
\hline $75-79$ yr & 11.0 & 13.8 & 0.230 & 13.8 & 12.8 & 0.782 \\
\hline$\geq 80 \mathrm{yr}$ & 9.8 & 11.1 & 0.511 & 9.9 & 10.7 & 0.751 \\
\hline \multicolumn{7}{|l|}{ Hospital bed size } \\
\hline Small & 3.4 & 16.5 & $<0.001$ & 5.5 & 7.2 & 0.550 \\
\hline Medium & 14.9 & 12.0 & 0.446 & 13.6 & 15.4 & 0.683 \\
\hline Large & 81.7 & 71.6 & 0.144 & 80.9 & 77.4 & 0.468 \\
\hline Teaching hospital & 73.6 & 74.3 & 0.933 & 82.2 & 79.3 & 0.518 \\
\hline Mean annual TEVAR volume $(n)$ & 8.2 & 27.3 & $<0.001$ & 15.1 & 15.4 & 0.894 \\
\hline \multicolumn{7}{|l|}{ Comorbid conditions } \\
\hline Cardiac comorbidities & 54.9 & 39.9 & $<0.001$ & 44.9 & 42.1 & 0.558 \\
\hline Cardiac arrhythmia & 34.1 & 14.8 & $<0.001$ & 15.3 & 16.8 & 0.648 \\
\hline Chronic $\mathrm{CHF}^{*}$ & 11.8 & 9.2 & 0.186 & 9.3 & 9.5 & 0.940 \\
\hline Coronary disease & 10.1 & 17.5 & 0.004 & 19.4 & 17.0 & 0.556 \\
\hline Valvular disease & 20.3 & 10.7 & 0.003 & 12.7 & 12.8 & 0.976 \\
\hline Chronic pulmonary disease & 15.0 & 23.9 & $<0.001$ & 25.3 & 24.0 & 0.755 \\
\hline Chronic renal failure & 10.0 & 10.9 & 0.679 & 7.8 & 10.1 & 0.346 \\
\hline Coagulopathy & 19.9 & 8.1 & $<0.001$ & 9.0 & 10.3 & 0.666 \\
\hline Deficiency anemias & 15.4 & 14.3 & 0.674 & 16.8 & 15.5 & 0.693 \\
\hline Diabetes & 7.7 & 12.3 & 0.012 & 10.8 & 11.9 & 0.691 \\
\hline Hypertension & 65.8 & 66.0 & 0.950 & 65.8 & 66.3 & 0.922 \\
\hline Obesity & 7.1 & 4.6 & 0.142 & 3.9 & 4.4 & 0.782 \\
\hline Other neurological disorders & 5.1 & 3.1 & 0.198 & 2.5 & 2.8 & 0.876 \\
\hline Paralysis & 5.4 & 5.1 & 0.838 & 5.3 & 6.2 & 0.687 \\
\hline Peripheral vascular disease & 14.9 & 32.6 & $<0.001$ & 25.6 & 25.7 & 0.980 \\
\hline
\end{tabular}

* CHF: congestive heart failure.

hospital TEVAR volumes reached 30 per year. In fact the TBAD in-hospital mortality rate for hospitals performing less than 30 procedures per year was more than twice the rate seen in hospitals that performed more than 30 per year $(<30$ $=11.3 \%, \geq 30=4.8 \% ; P=.047)$.

\section{Discussion}

We looked at TEVAR and open repair use for type B aortic dissection over a four-year period and compared outcomes. To control for selection bias we used a propensity score model to create matched cohorts of patients for the comparisons. Among patients treated emergently, inhospital mortality was significantly lower with TEVAR than open surgery $(10.8 \%$ versus $17.5 \%, P=.045)$. This finding is consistent with other reports in the literature. In patients with complicated TBAD, Zeeshan et al. [14] demonstrated significantly lower 30 -day mortality ( $4 \%$ versus $40 \% ; P$ $=.006)$ among TEVAR recipients $(n=45)$ compared to open repair recipients $(n=20)$. Also, in patients with complicated TBAD, International Registry of Acute Aortic Dissection (IRAD) investigators demonstrated significantly lower inhospital mortality among TEVAR recipients $(10.6 \%$ versus $33.9 \%, P=.002$ ) as well as lower rates of stroke and acute renal failure $(20.8 \%$ versus $40.0 \%, P=.04)$ [6]. In a recent 
TABLE 3: Baseline characteristics of electively admitted patients undergoing open surgical repair or TEVAR for type B dissections from 2005 to 2008 .

\begin{tabular}{|c|c|c|c|c|c|c|}
\hline \multirow[t]{2}{*}{ Variable } & \multicolumn{3}{|c|}{ Unmatched cohort } & \multicolumn{3}{|c|}{ Matched cohort } \\
\hline & $\begin{array}{c}\text { Open repair } \\
(n=680)\end{array}$ & $\begin{array}{c}\text { TEVAR } \\
(n=567)\end{array}$ & $P$ value & $\begin{array}{c}\text { Open repair } \\
(n=282)\end{array}$ & $\begin{array}{c}\text { TEVAR } \\
(n=282)\end{array}$ & $P$ value \\
\hline & \multicolumn{3}{|c|}{ Mean or \% of patients } & \multicolumn{3}{|c|}{ Mean or $\%$ of patients } \\
\hline Female sex & 29.5 & 25.9 & 0.520 & 32.0 & 26.6 & 0.531 \\
\hline \multicolumn{7}{|l|}{ Age } \\
\hline Mean age (years) & 58.3 & 63.0 & 0.008 & 60.7 & 62.0 & 0.485 \\
\hline$<60 \mathrm{yr}$ & 50.4 & 37.2 & 0.040 & 46.1 & 44.3 & 0.842 \\
\hline $60-64 \mathrm{yr}$ & 12.2 & 14.0 & 0.637 & 11.8 & 11.9 & 0.992 \\
\hline $65-69 \mathrm{yr}$ & 11.9 & 14.7 & 0.548 & 10.8 & 12.4 & 0.822 \\
\hline $70-74 \mathrm{yr}$ & 11.0 & 19.1 & 0.080 & 15.9 & 17.5 & 0.822 \\
\hline $75-79$ yr & 10.2 & 11.0 & 0.852 & 8.6 & 8.7 & 0.978 \\
\hline$\geq 80 \mathrm{yr}$ & 4.3 & 4.1 & 0.943 & 6.9 & 5.3 & 0.758 \\
\hline \multicolumn{7}{|l|}{ Hospital bed size } \\
\hline Small & 4.4 & 17.3 & 0.022 & 7.9 & 9.3 & 0.739 \\
\hline Medium & 18.5 & 16.1 & 0.743 & 19.5 & 19.9 & 0.970 \\
\hline Large & 77.1 & 66.6 & 0.278 & 72.6 & 70.8 & 0.863 \\
\hline Teaching hospital & 79.6 & 75.4 & 0.632 & 79.1 & 85.7 & 0.483 \\
\hline Mean annual TEVAR volume $(n)$ & 9.3 & 28.5 & $<0.001$ & 14.1 & 14.7 & 0.656 \\
\hline \multicolumn{7}{|l|}{ Comorbid conditions } \\
\hline Cardiac comorbidities & 53.1 & 39.6 & 0.048 & 42.2 & 37.5 & 0.635 \\
\hline Cardiac arrhythmia & 18.8 & 17.0 & 0.700 & 23.1 & 16.6 & 0.323 \\
\hline Chronic CHF* & 11.1 & 10.2 & 0.828 & 12.2 & 11.9 & 0.973 \\
\hline Coronary disease & 16.2 & 23.1 & 0.233 & 15.9 & 16.7 & 0.916 \\
\hline Valvular disease & 27.9 & 7.3 & $<0.001$ & 8.3 & 11.8 & 0.504 \\
\hline Chronic pulmonary disease & 18.2 & 23.6 & 0.309 & 19.5 & 24.4 & 0.496 \\
\hline Chronic renal failure & 12.7 & 11.4 & 0.754 & 10.5 & 15.5 & 0.445 \\
\hline Coagulopathy & 15.7 & 3.7 & 0.004 & 3.5 & 5.1 & 0.681 \\
\hline Deficiency anemias & 10.2 & 8.4 & 0.632 & 10.5 & 12.0 & 0.801 \\
\hline Diabetes & 9.8 & 19.6 & 0.030 & 10.7 & 14.0 & 0.554 \\
\hline Hypertension & 65.4 & 85.0 & $<0.001$ & 72.0 & 76.0 & 0.600 \\
\hline Obesity & 8.3 & 13.9 & 0.129 & 11.0 & 8.6 & 0.690 \\
\hline Other neurological disorders & 4.4 & 3.8 & 0.793 & 1.9 & 3.9 & 0.566 \\
\hline Paralysis & 3.0 & 0.9 & 0.269 & 1.7 & 1.8 & 0.967 \\
\hline Peripheral vascular disease & 19.7 & 27.6 & 0.131 & 21.3 & 27.7 & 0.409 \\
\hline
\end{tabular}

${ }^{*}$ CHF: congestive heart failure.

meta-analysis of TEVAR use in complicated acute type B dissections, Luebke and Brunkwall [15] reported an inhospital mortality rate of $11.5 \%$.

In contrast to what we observed with emergently admitted patients, TEVAR did not appear to have an impact on the mortality of nonemergent TBAD patients (3.3\% versus $5.6 \%$, $P=.464)$. However, the more relevant question for patients with uncomplicated type B aortic dissection is how the outcomes of TEVAR compare to medical therapy, the standard of care for this disease. Unfortunately, our study could not address this question as large datasets like the NIS do not contain anatomical information about the disease, which would be needed to distinguish type A and type B dissections.
Our ability to make this distinction in surgical patients relied on the coding of associated aortic arch and aortic valve procedures, commonly required to repair type A dissections. It is clear that comparing the outcomes of medical therapy to TEVAR for uncomplicated type B dissections will require primary data collection, preferably in the form of a randomized controlled trial.

In looking at the relationship between TEVAR volume and outcome of treatment in emergently treated TBAD patients, we observed over a fourfold difference in mortality (13.4\% versus $2.9 \%$ ) between the lowest volume group (1-4 TEVAR procedures/year) and the highest volume group (over 55 TEVAR procedures/year). Hospitals that perform less than 
TABLE 4: In-hospital outcomes after open repair or TEVAR in a matched cohort of emergently admitted patients.

\begin{tabular}{lccc}
\hline & $\begin{array}{c}\text { Open repair } \\
(n=991)\end{array}$ & $\begin{array}{c}\text { TEVAR } \\
(n=991)\end{array}$ & $P$ value \\
\hline mean or \% of patients \\
\hline Acute renal failure & 17.5 & 10.8 & 0.045 \\
Cardiac complications & 27.3 & 16.8 & 0.008 \\
Neurological complications & 16.6 & 8.9 & 0.029 \\
Paraplegia & 11.0 & 9.3 & 0.561 \\
Posthemorrhagic anemia & 2.5 & 3.2 & 0.705 \\
Postoperative hemorrhage & 13.5 & 12.1 & 0.006 \\
Pulmonary complications & 34.4 & 9.2 & 0.209 \\
Stroke & 6.2 & 3.7 & 0.052 \\
Thrombectomy or & 1.9 & 5.0 & 0.239 \\
embolectomy & 15.0 & 13.9 & 0.133 \\
Mean length of stay (days) & & & \\
\hline
\end{tabular}

TABLE 5: In-hospital outcomes after open repair or TEVAR in a matched cohort of electively admitted patients.

\begin{tabular}{lccc}
\hline & $\begin{array}{c}\text { Open repair } \\
(n=282)\end{array}$ & $\begin{array}{c}\text { TEVAR } \\
(n=282)\end{array}$ & $P$ value \\
\hline mean or \% of patients \\
\hline Acute renal failure & 5.6 & 3.3 & 0.464 \\
Cardiac complications & 13.0 & 1.7 & 0.021 \\
Neurological complications & 15.8 & 3.6 & 0.021 \\
Paraplegia & 1.9 & 5.4 & 0.348 \\
Posthemorrhagic anemia & 17.3 & 0.0 & \\
Postoperative hemorrhage & 19.1 & 3.5 & 0.017 \\
Pulmonary complications & 35.0 & 16.2 & 0.009 \\
Stroke & 1.9 & 3.6 & 0.034 \\
Thrombectomy or & 1.8 & 7.3 & 0.600 \\
embolectomy & 11.3 & 7.7 & 0.171 \\
Mean length of stay (days) & & & \\
\hline
\end{tabular}

thirty TEVAR procedures annually had more than twofold higher in-hospital mortality for emergent TBAD patients than hospitals performing more than 30 TEVAR procedures a year $(11.3 \%$ versus $4.8 \%, P=.047)$. Although this analysis did not adjust for differences between the volume groups, which would have required a larger sample size, our restricting the analysis to the subgroup who was hospitalized emergently does help to minimize the differences between the volume groups. Our finding is consistent with others. In a meta-analysis of 609 patients undergoing TEVAR for aortic dissection (96\% TBAD), Eggebrecht et al. [5] concluded that surgeons' experience with TEVAR influenced outcomes because hospitals that performed more than twenty TEVAR procedures had significantly lower 30-day mortality than hospitals with less than twenty procedures $(3.2 \%$ versus $8.5 \% ; P<.001)$.

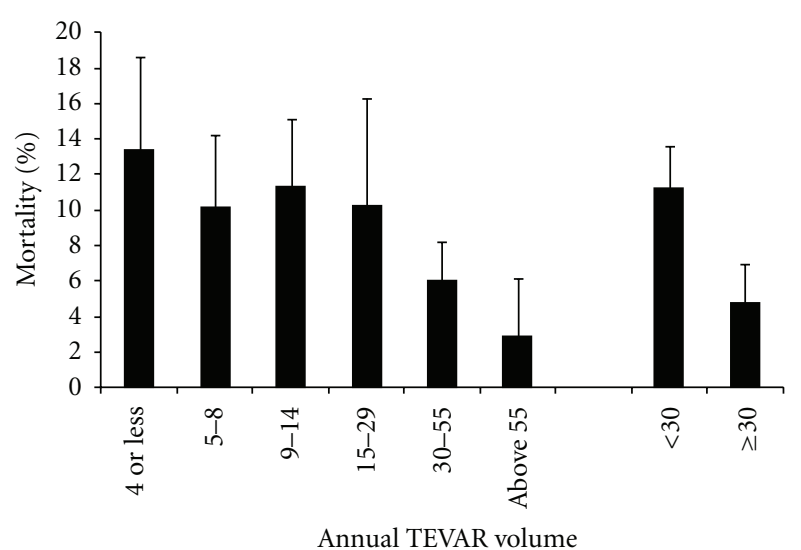

FIGURE 1: In-hospital mortality rates for emergently admitted TBAD patients undergoing TEVAR based on the annual hospital volume of TEVAR procedures performed. The following are the number of emergently admitted TBAD patients treated with endovascular repair in each TEVAR volume group: $1-4(n=225)$, 5-8 $(n=237), 9-14(n=217), 15-29(n=239), 30-55(n=241)$, greater than $55(n=167)$, less than $30(n=917), 30$ or more $(n=$ 408).

One limitation of our study is that it is observational and carries all the potential biases inherent to such studies. For instance, the subgroups of patients who underwent TEVAR and open repair differed substantially (Tables 2 and 3 ). We adjusted our comparisons for such differences by comparing propensity score-matched cohorts; however, it is possible that there is still some bias in the analyzed cohorts due to confounders that were not recognized. Furthermore, the comorbidity data, which was the basis for the comparisons between treatment groups, was originally collected for administrative purposes and subject to coding errors. Another important limitation to our study is that it does not address long-term outcomes. Complications unique to treatment with TEVAR, such as endoleak, graft migration, and retrograde type A dissection, can contribute to mortality and complications after a patient is discharged from the hospital $[16,17]$. Longitudinal analysis in the form of randomized controlled clinical trials is needed in order to determine the long-term outcomes of TEVAR used for type $\mathrm{B}$ dissections and to ascertain whether favorable inhospital outcomes for TEVAR in emergently admitted TBAD patients persist over time. The recent INSTEAD trial was the first prospective, randomized, and controlled comparison of TEVAR and medical treatment in uncomplicated TBAD, and it showed that there was no difference in oneyear mortality between TEVAR and medical therapy alone, despite significantly greater aortic remodeling in TEVAR [18]. However, INSTEAD was not appropriately powered to find a difference with the high survival rates they observed in the medical therapy group. Moreover, INSTEAD did not restrict enrollment to current definitions of acute uncomplicated TBAD, which many believe is the subgroup with greatest chance of showing a benefit to TEVAR [8]. Many of these limitations are being addressed by the ongoing ADSORB clinical trial [19]. 


\section{Conclusions}

Our study demonstrates that endovascular repair is becoming an important treatment modality for type B dissection. Approximately $31.5 \%$ of the surgical repairs of TBAD in the United States are performed using this modality. Our analysis of the NIS dataset, using propensity score matching, demonstrated that TEVAR outperforms open surgery among emergently admitted patients with type B aortic dissection, both in terms of in-hospital mortality and morbidity. This was not the case for electively admitted patients, where TEVAR appeared to impart a short-term morbidity benefit only. We observed a significant volume outcome relationship between overall TEVAR use and in-hospital mortality rates, which, if confirmed through additional studies, should guide institutional targets for optimal outcomes of therapy.

\section{References}

[1] P. G. Hagan, C. A. Nienaber, E. M. Isselbacher et al., "The International Registry of Acute Aortic Dissection (IRAD): new insights into an old disease," Journal of the American Medical Association, vol. 283, no. 7, pp. 897-903, 2000.

[2] R. Erbel, F. Alfonso, C. Boileau et al., "Diagnosis and management of aortic dissection: recommendations of the Task Force on Aortic Dissection, European Society of Cardiology," European Heart Journal, vol. 22, no. 18, pp. 1642-1681, 2001.

[3] W. D. Clouse, J. W. Hallett, H. V. Schaff et al., "Acute aortic dissection: population-based incidence compared with degenerative aortic aneurysm rupture," Mayo Clinic Proceedings, vol. 79, no. 2, pp. 176-180, 2004.

[4] F. B. Gonçalves, R. Metz, J. M. Hendriks et al., "Decisionmaking in type-B dissection: current evidence and future perspectives," Journal of Cardiovascular Surgery, vol. 51, no. 5, pp. 657-667, 2010.

[5] H. Eggebrecht, C. A. Nienaber, M. Neuhäuser et al., "Endovascular stent-graft placement in aortic dissection: a metaanalysis," European Heart Journal, vol. 27, no. 4, pp. 489-498, 2006.

[6] R. Fattori, T. T. Tsai, T. Myrmel et al., "Complicated acute type B dissection: is surgery still the best option?. A report from the International Registry of Acute Aortic Dissection," JACC: Cardiovascular Interventions, vol. 1, no. 4, pp. 395-402, 2008.

[7] J. E. Bavaria, J. J. Appoo, M. S. Makaroun, J. Verter, Z. F. Yu, and R. S. Mitchell, "Endovascular stent grafting versus open surgical repair of descending thoracic aortic aneurysms in low-risk patients: a multicenter comparative trial," Journal of Thoracic and Cardiovascular Surgery, vol. 133, no. 2, pp. 369377.e4, 2007.

[8] I. Akin, S. Kische, T. C. Rehders, H. Ince, and C. A. Nienaber, "Thoracic endovascular stent-graft therapy in aortic dissection," Current Opinion in Cardiology, vol. 25, no. 6, pp. 552-559, 2010.

[9] T. T. Tsai, A. Evangelista, C. A. Nienaber et al., "Partial thrombosis of the false lumen in patients with acute type B aortic dissection," New England Journal of Medicine, vol. 357, no. 4, pp. 349-359, 2007.

[10] S. D. Xu, F. J. Huang, J. F. Yang et al., "Endovascular repair of acute type B aortic dissection: early and mid-term results," Journal of Vascular Surgery, vol. 43, no. 6, pp. 1090-1095, 2006.

[11] R. J. Feezor, T. D. Martin, P. J. Hess, T. M. Beaver, C. T. Klodell, and W. A. Lee, "Early outcomes after endovascular management of acute, complicated type B aortic dissection," Journal of Vascular Surgery, vol. 49, no. 3, pp. 561-566, 2009.

[12] J. Xiong, B. Jiang, W. Guo, S. M. Wang, and X. Y. Tong, "Endovascular stent graft placement in patients with type B aortic dissection: a meta-analysis in China," Journal of Thoracic and Cardiovascular Surgery, vol. 138, no. 4, pp. 865-872.e1, 2009.

[13] T. Sachs, F. Pomposelli, R. Hagberg et al., "Open and endovascular repair of type B aortic dissection in the Nationwide Inpatient Sample," Journal of Vascular Surgery, vol. 52, no. 4, pp. 860-866, 2010.

[14] A. Zeeshan, E. Y. Woo, J. E. Bavaria et al., "Thoracic endovascular aortic repair for acute complicated type B aortic dissection: superiority relative to conventional open surgical and medical therapy," Journal of Thoracic and Cardiovascular Surgery, vol. 140, no. 6, supplement, pp. S109-S115, 2010.

[15] T. Luebke and J. Brunkwall, "Outcome of patients with open and endovascular repair in acute complicated type B aortic dissection: a systematic review and meta-analysis of case series and comparative studies," Journal of Cardiovascular Surgery, vol. 51, no. 5, pp. 613-632, 2010.

[16] M. Grabenwoger, T. Fleck, M. Ehrlich et al., "Secondary surgical interventions after endovascular stent-grafting of the thoracic aorta," European Journal of Cardio-thoracic Surgery, vol. 26, no. 3, pp. 608-613, 2004.

[17] B. Neuhauser, A. Greiner, W. Jaschke, A. Chemelli, and G. Fraedrich, "Serious complications following endovascular thoracic aortic stent-graft repair for type B dissection," European Journal of Cardio-Thoracic Surgery, vol. 33, no. 1, pp. 58-63, 2008.

[18] C. A. Nienaber, S. Kische, I. Akin et al., "Strategies for subacute/chronic type B aortic dissection: the Investigation of Stent Grafts in Patients with Type B Aortic Dissection (INSTEAD) trial 1-year outcome," Journal of Thoracic and Cardiovascular Surgery, vol. 140, no. 6, supplement, pp. S101S108, 2010.

[19] D. G. Tang and M. D. Dake, "TEVAR for acute uncomplicated aortic dissection: immediate repair versus medical therapy," Seminars in Vascular Surgery, vol. 22, no. 3, pp. 145-151, 2009. 


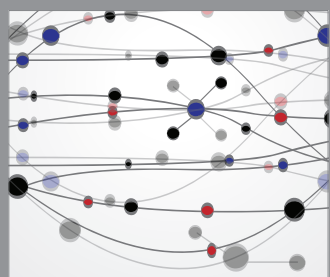

The Scientific World Journal
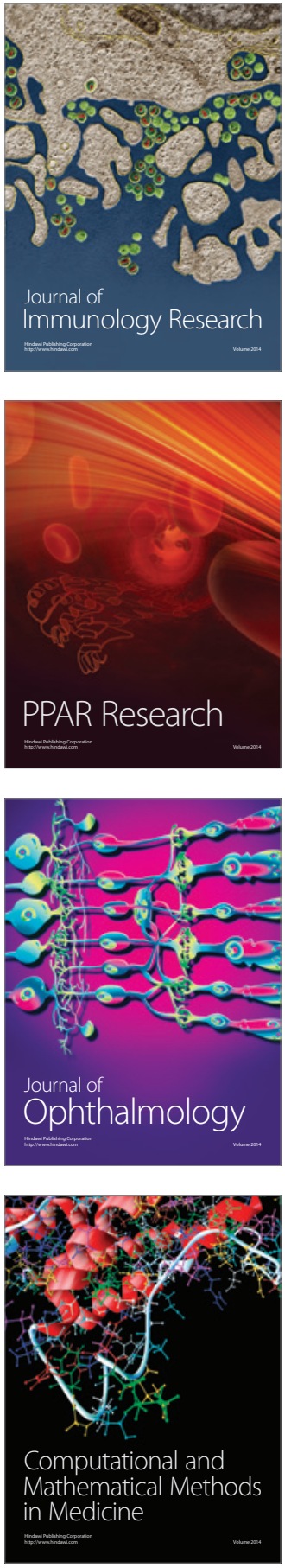

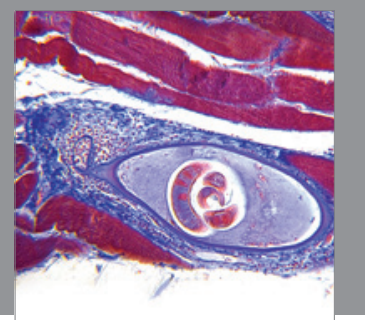

Gastroenterology

Research and Practice
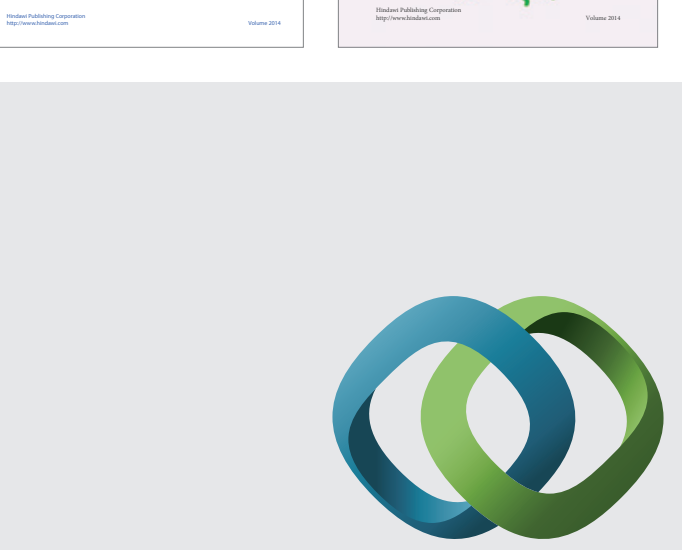

\section{Hindawi}

Submit your manuscripts at

http://www.hindawi.com
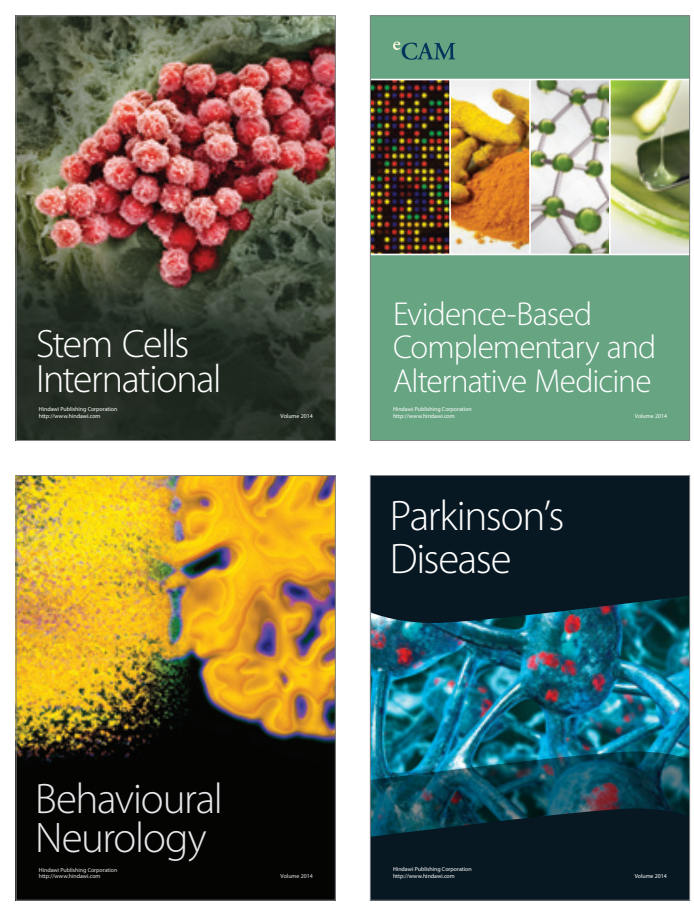

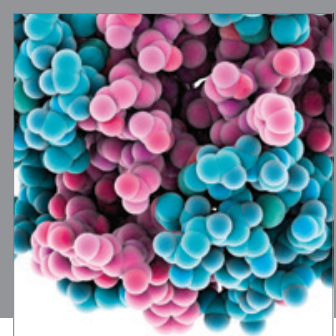

Journal of
Diabetes Research

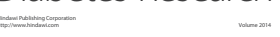

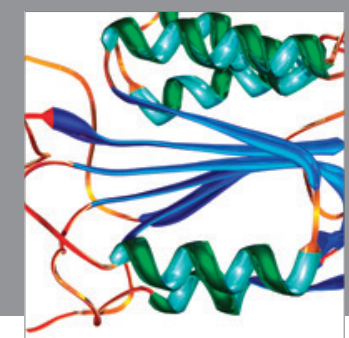

Disease Markers
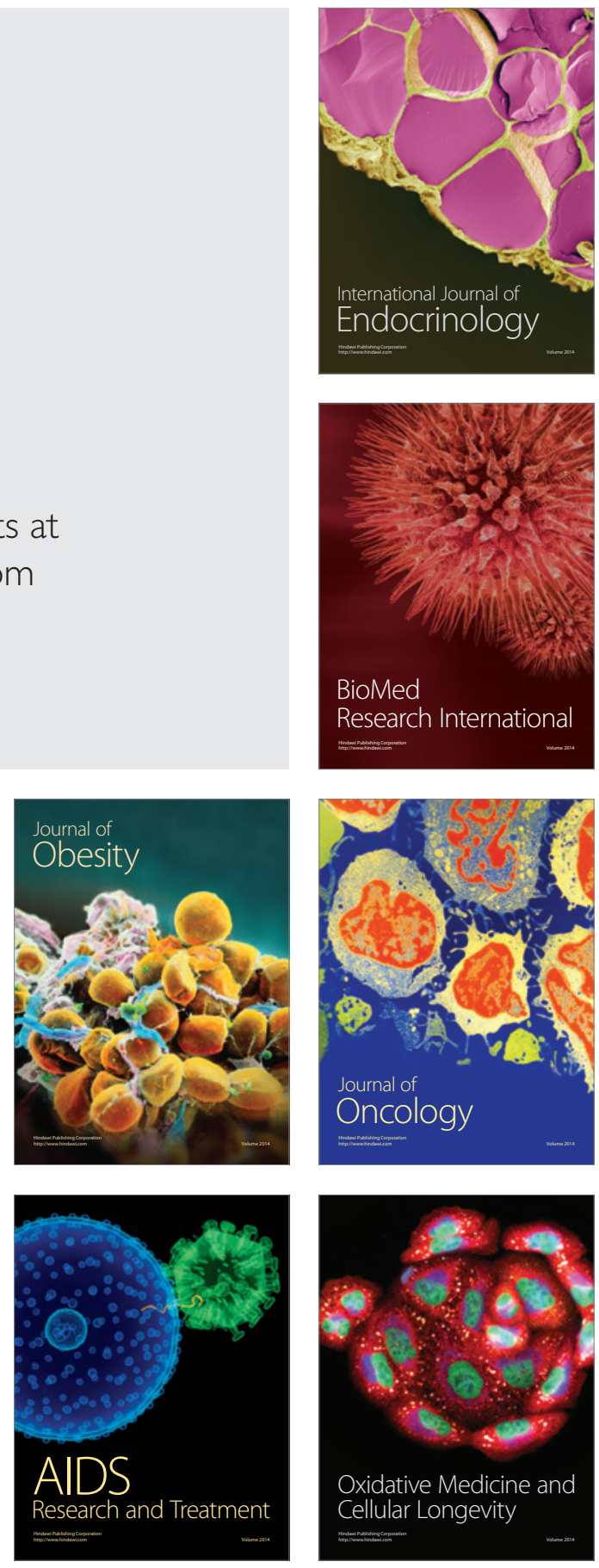